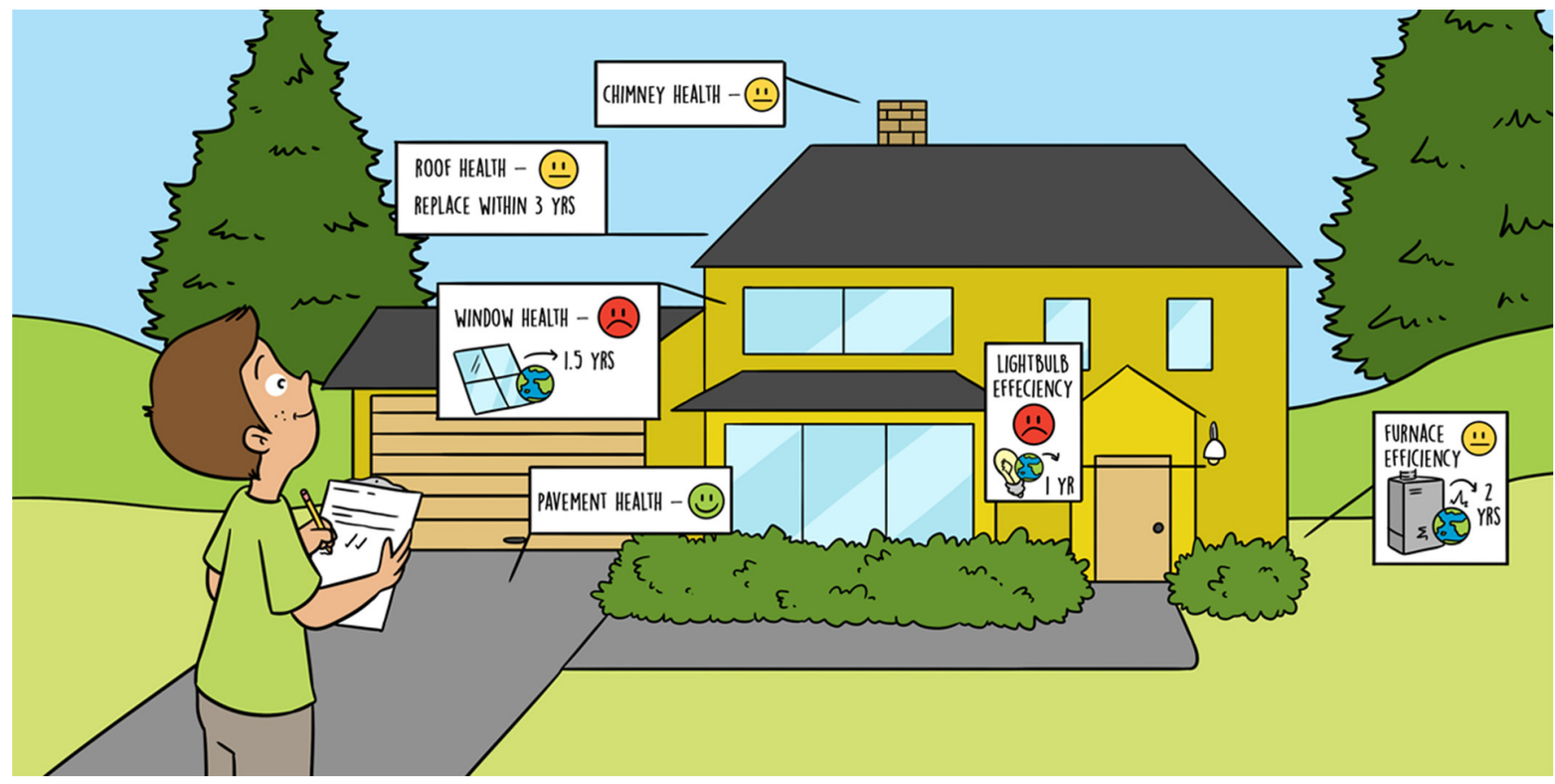

\title{
WHAT IS THE BEST WAY TO TAKE CARE OF BUILDINGS?
}

\section{Jamie Filer ${ }^{*}$, Steven Schuldt and Andrew Hoisington}

Graduate School of Engineering and Management, Air Force Institute of Technology, Wright-Patterson AFB, OH, United States

\section{YOUNG REVIEWER:}

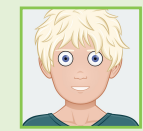

KALVIN

AGE: 8
We spend most of our time inside buildings, but did you know that owning a building can be very expensive? There are many tasks we need to do on a regular basis to keep our buildings in good shape. These tasks are called maintenance, and they require materials and labor, which cost money. Therefore, building owners try to keep their buildings in good shape for as long as possible. Buildings can also have negative impacts on the environment, which we want to avoid. By analyzing how a building's condition changes over its lifetime, we can predict when it will need maintenance. This allows us to fix problems before they become more expensive and worse on the environment. To do that, engineers use a process called life-cycle analysis to make decisions on where and when to invest time and money on building maintenance. In this article, we will explain life-cycle analysis and use the example of a house to describe the concept. 
Figure 1

Components of a house that will need repair include the roof, air conditioner, siding, and more. Each of these components may fail after a different amount of time.

\section{COMPONENT}

A part that makes up a whole when combined with other parts.

\section{MAINTENANCE}

The tasks that must be done to keep property or equipment in good shape.

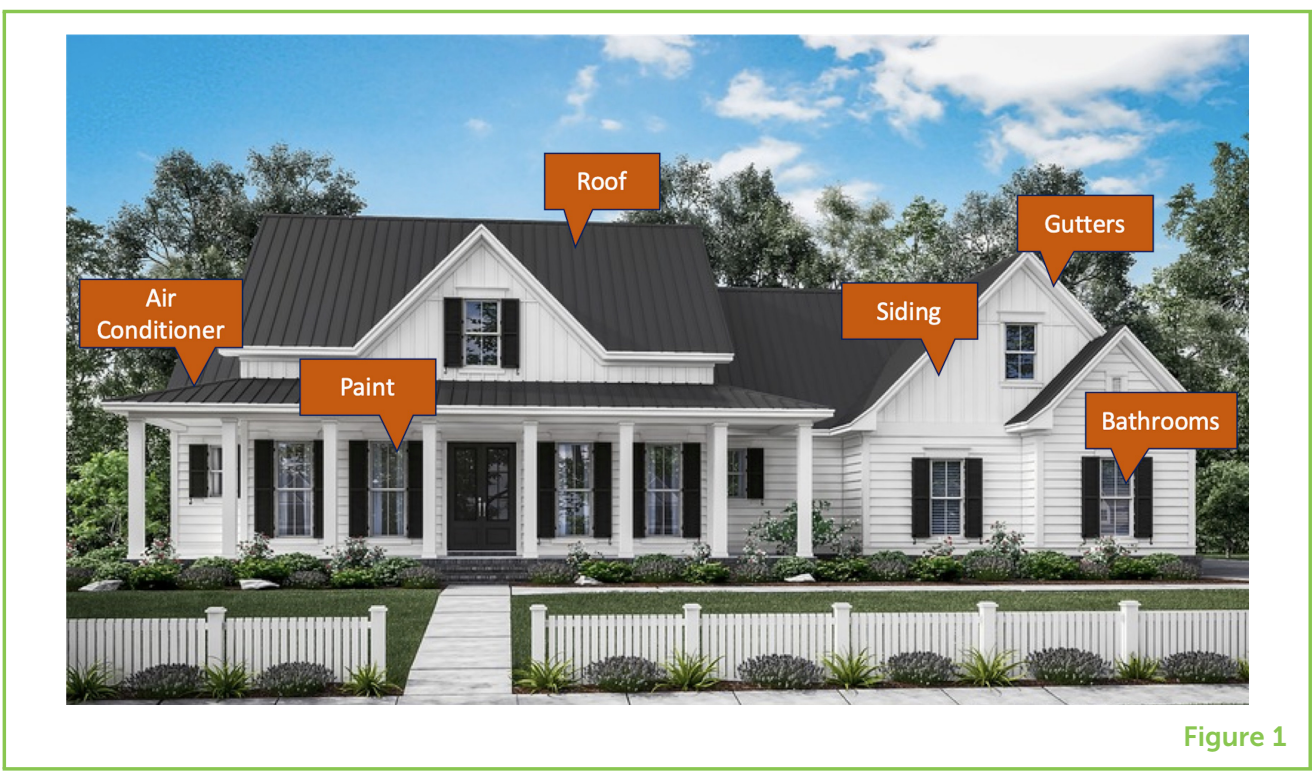

\section{WHAT DO WE NEED TO KNOW TO KEEP BUILDINGS HEALTHY?}

Buildings, such as your house, consist of many parts. These parts are called components, and each one serves a purpose. The components of a house include the foundation, roof, gutters, windows, siding, electrical system, plumbing, walls, and more. All of the components must work together to fulfill the building's purpose [1]. If one of the components fails, the entire building may not be very useful. Imagine a storm suddenly blows a tree over, and it pokes a hole in the roof of your house. The rest of the house's components, like the plumbing, might work fine. But the roof failure means that the building fails its purpose, which is to keep you warm and dry.

Buildings, like your house, cost money to build or buy, but on top of this initial cost, there are ongoing maintenance and repair costs. The maintenance and repair costs include many tasks that require both time and money. For example, as shown in Figure 1, a house needs a new roof every 20 years; the gutters need to be cleaned every fall; the air conditioning parts need to be cleaned every few months; holes in the siding need to be repaired frequently; the bathrooms need to be renovated every 20 years; your sister's room needs to be repainted when her favorite color changes; and more. The number of tasks over your house's long lifetime, known as its life cycle, really add up. This is what makes the maintenance phase so expensive. However, we invest time and money into our houses because maintenance helps make their life cycles longer.

In addition to costing money, each building also has an impact on the environment around it. These impacts are often negative [2]. For example, the land your house was built on was cleared of plants and trees. Removing plants forces the animals that lived there to move, 


\section{LIFE-CYCLE}

\section{ANALYSIS}

A way to look at the costs and environmental impacts of repair on a building throughout its entire life.

\section{ANALYSIS}

A detailed study of something complex in order to understand how it works.

\section{METHODICAL}

Following a clear set of steps that can be repeated over and over. which is bad for the environment. The wood used to construct the walls was collected with equipment that runs on fossil fuels and pollutes the air. When the roof gets replaced, the old material is taken to a landfill. And if we do not take care of the air conditioning system properly, the fluids needed to run it can be harmful to the air we breathe.

Let us think even bigger than a single component. As you may imagine, larger buildings, like factories, require more maintenance than your house because they have more components. If a factory has five air conditioning units instead of one, how can the owners possibly track when each air conditioning unit needs to be replaced? The components that make up a building cannot last forever. All equipment and materials break down over time. Eventually, some component will be in such bad condition that it must be repaired or replaced. However, each component has its own, unique life cycle. The air conditioning parts may last 6 or 7 years, but the building's roof might last 20 years. Building owners collect data on each component to see how long it usually lasts. Collecting data is the first step in performing a life-cycle analysis, which helps keep maintenance and repair tasks organized.

\section{WHY MAINTAIN BUILDINGS WITH LIFE-CYCLE ANALYSIS?}

Life-cycle analysis is a methodical and scientific tool used to analyze a building throughout its lifetime, in order to make decisions regarding maintenance and repair [3, 4]. This definition sounds complicated, but we will break it down. "Methodical" means that the life-cycle analysis follows a clear set of steps that we can repeat over and over. Being methodical is most important for big buildings with many components. "Scientific" means that the process is backed by data and research. Engineers have developed multiple ways to predict how long a building will last and how much it will impact the environment. Math equations make this possible. The phrase "throughout its lifetime" means we collect data on the condition of the building at multiple times. We want to learn about the building's condition at the beginning of its life, the end of its life, and every point in between. We cannot predict the exact time that a building will need maintenance, because that depends on many factors. These factors include weather, how much the building is used, and how much maintenance we do [1]. However, by analyzing a lot of data, we can make reasonable predictions. Finally, "make decisions" refers to why we chose to conduct a life-cycle analysis. Typically, we use data to make decisions on how to spend our money. We want to know when to repair each component. Again, repairs can help buildings last longer and decrease their impact on the environment. Repairs are costly, however, and building owners also want to minimize their costs. 
Figure 2

(A) If no repairs are completed, a house will eventually fail. (B) However, if repairs are done before failure, the house will last longer Maintenance and repairs can increase the house's life, and some repairs can reduce the house's cost and environmental impact.
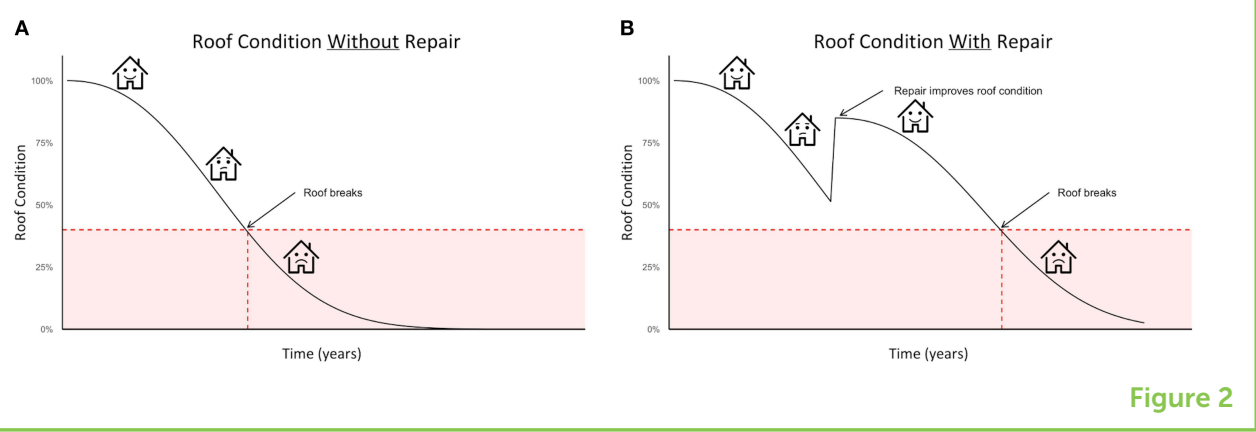

Figure 2A shows when a building component, like the roof, would normally fail if no maintenance or repair work was done. The roof goes from good condition to average condition to bad condition over time. However, through proper life-cycle analysis, engineers can estimate when components are most likely to fail. In Figure 2A, we show a roof failing after a few years. We made this prediction based on experience with many buildings, and most of those roofs failed around the same time. With this knowledge, we can plan maintenance and repair projects before the roof caves in completely. The most efficient time to invest in repairs is before failure [1]. Because we know when the roof is likely to fail, Figure $2 \mathrm{~B}$ shows a repair being completed before that failure time. The repair improves the building's condition right away. After the repair, the roof still goes from good condition to average condition to bad condition. However, this happens at a later time than in Figure 2A. Each maintenance or repair task can increase the building's life by a few months or even years. In the end, the roof's life cycle has been increased. Additionally, certain maintenance tasks can also reduce the building's environmental impact. For example, we can trade out old, incandescent light bulbs for more efficient, earth-friendly light-emitting diodes (LEDs). This task will decrease the amount of energy needed to light the building. This is both cost-effective and better for the environment.

Let us consider your house again. Your parents may clean the gutters every fall, to remove the leaves and branches that collect. They could clean the gutters every week, but that would take a lot of time. What if your parents waited and only cleaned up once every 5 years? Then the gutters could get clogged and your roof might start to leak. A leaky roof is much more expensive to fix than cleaning the gutters. Plus, fixing the roof would require you to dispose of shingles, wood, and nails, which is bad for the environment. This example shows that there is a best time to invest in maintenance and repair projects. Doing tasks too early is wasteful. But, doing tasks too late can allow small problems to grow into larger, more expensive problems. Analyzing data from a building can help us estimate when components will fail. We also know that the best time to complete a repair is just before the failure point. This allows us to optimize the building's performance and environmental impact at the lowest cost possible. 


\section{CONCLUSION}

Building life-cycle analysis is a concept we use to take care of our buildings. We analyze the building's condition throughout its life in order to pick the best time to invest in repair and maintenance tasks. Investing at the right time helps the building last longer and minimize its impact on the environment. This is simple for one component, but it can get complicated quickly. Buildings have hundreds of components, and each one has a different life expectancy. The life-cycle analysis process provides clear steps to follow. By following these steps, owners can decide on the best time to invest in their building.

\section{AUTHOR CONTRIBUTIONS}

$\mathrm{JF}, \mathrm{SS}$, and $\mathrm{AH}$ contributed the conception and design of the paper. JF wrote the first draft of the manuscript. SS and AH revised the sections of the manuscript. AH provided the content expertise. All authors contributed to the manuscript revision, read, and approved the submitted version.

\section{REFERENCES}

1. Grussing, M. N., and Marrano, L. R. 2007. "Building component lifecycle repair/replacement model for institutional facility management," in Proceedings of the 2007 International Workshop on Computing in Civil Engineering, eds L. Soibelman and B. Akinci (Pittsburgh, PA: American Society of Civil Engineers). p. 550-57. doi: 10.1061/40937(261)65

2. Medineckiene, M., Turskis, Z., and Zavadskas, E. K. 2010. Sustainable construction taking into account the building impact on the environment. J. Environ. Eng. Landsc. Manag. 18:118-27. doi: 10.3846/jeelm.2010.14

3. ISO 14040. 2006. Environmental Management-Life Cycle Assessment-Principles and Framework. ISO 14040. International Organization for Standardization. Available online at: https://www.iso.org/obp/ui/\#iso:std:iso:14040:ed-2:v1:en

4. Bayer, C., Gamble, M., Gentry, R., and Joshi, S. 2010. AlA Guide to Building Life Cycle Assessment in Practice. Washington, DC: The American Institute of Architects.

SUBMITTED: 18 June 2019; ACCEPTED: 20 February 2020; PUBLISHED ONLINE: 10 March 2020.

EDITED BY: Anna Regoutz, University College London, United Kingdom

CITATION: Filer J, Schuldt S and Hoisington A (2020) What Is the Best Way to Take Care of Buildings? Front. Young Minds 8:28. doi: 10.3389/frym.2020.00028

CONFLICT OF INTEREST: The authors declare that the research was conducted in the absence of any commercial or financial relationships that could be construed as a potential conflict of interest. 

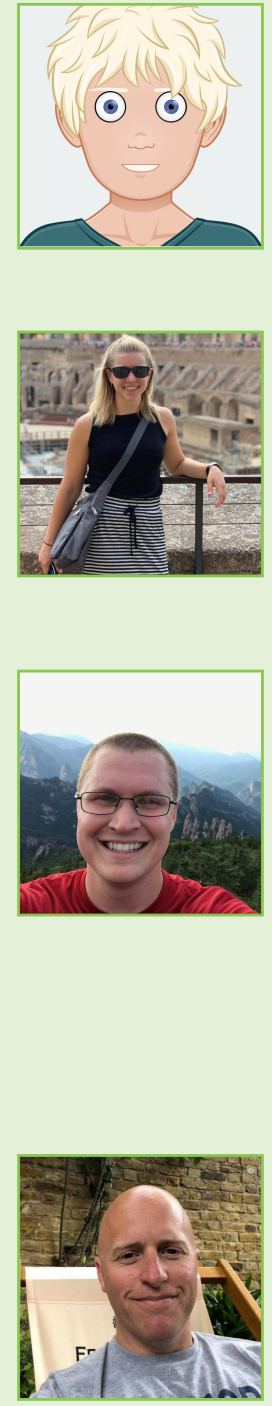

COPYRIGHT @ 2020 Filer, Schuldt and Hoisington. This is an open-access article distributed under the terms of the Creative Commons Attribution License (CC BY). The use, distribution or reproduction in other forums is permitted, provided the original author(s) and the copyright owner(s) are credited and that the original publication in this journal is cited, in accordance with accepted academic practice. No use, distribution or reproduction is permitted which does not comply with these terms.

\section{YOUNG REVIEWER}

\section{KALVIN, AGE: 8}

Kalvin loves animals, drama, and dancing. He enjoys playing basketball with his school team.

\section{AUTHORS}

\section{JAMIE FILER}

Jamie Filer is a Captain in the United States Air Force and a master's candidate at the Air Force Institute of Technology. In her 5 years of service, Captain Filer has held a variety of jobs as a civil engineer at bases in Delaware, Afghanistan, and Ohio. Her research uses life-cycle analysis to evaluate the impact that buildings at remote military bases have on the environment. *jamie.filer@afit.edu

\section{STEVEN SCHULDT}

Steven Schuldt is a Major in the United States Air Force and currently teaches at the Air Force Institute of Technology at Wright-Patterson Air Force Base, Ohio. In his 12 years of service, Major Schuldt has held a variety of jobs as an Air Force Civil Engineer. He has worked at military bases all over the world, including South Carolina, Ohio, Illinois, Afghanistan, Tajikistan, Kyrgyzstan, Finland, Sweden, Jordan, and the Republic of Korea. Major Schuldt teaches and conducts research in construction management, which includes using life-cycle analysis to make better decisions.

\section{ANDREW HOISINGTON}

Andrew Hoisington is a Lieutenant Colonel in the United States Air Force. He has been a civil engineer for 19 years, enjoying his time in the field and the classroom. He has experience building and maintaining Air Force bases in Hawaii, Colorado, Ohio, South Korea, Portugal, Uzbekistan, Qatar, and Oman. He has taught engineering at the United States Air Force Academy and at the Air Force Institute of Technology. Currently, he is the lead professor in studies on Air Force asset management, which includes how to maintain buildings. 